\title{
Bridging the Gap: Why Strength and Conditioning Practitioners and Researchers Should Collaborate
}

\author{
Andrew Langford ${ }^{1}$ and Stephen P. Bird, Ph. D ${ }^{1,2}$. \\ ${ }^{1}$ International Universities Strength and Conditioning Association, ${ }^{2}$ School of Health and \\ Wellbeing, University of Southern Queensland, Ipswich QLD, Australia
}

Leading up to the launch of the International Universities Strength and Conditioning Association Journal (IUSCA Journal) the Editorial team are publishing a 'bridging the gap' series of articles about how to bridge the gap between strength and conditioning (S\&C) research and practice. We will be looking at how we can better work together as coaches and academics and we will be taking a closer look at the values of science and how we can apply them in practice. By drawing on the wisdom of experienced coaches and researchers, we will look at what this gap is and how we can help bridge it through increased collaboration and the removal of barriers to publication. In this first 'Bridging the Gap' article, we briefly discuss (1) what this gap is; (2) why it exists; and (3) potential solutions.

While coaches and practitioners wish to be holistic in their approach in order to navigate the complex and ambiguous grey areas of the real world, researchers and academics often take a reductionistic approach, looking ever closer at the fine details. ${ }^{1}$ Neither of these approaches are inherently 'wrong', but they are destined to operate at two ends of a spectrum. One approach looks to satisfy the principles of science and apply precise, mechanistic reasoning about the world, ${ }^{2}$ while the other is interested in real-world application and how complex variables interplay. ${ }^{3}$ Because of this, we find more and more emphasis occurs by specialists at each end of the spectrum, potentially leaving a void in the middle. Figure 1 displays the scientific research - coaching practice gap.

From a purely scientific perspective, it is understandable that athlete case-studies ${ }^{4-}$ ${ }^{6}$ and real-life applications are sometimes under-valued. It is difficult to draw conclusions and to separate correlation from causation. Statistical power is weak, and you may not be able to replicate the findings in any meaningful way. That said, at the other end of the spectrum, a purely reductionist viewpoint will likely lack realworld applicability and ecological validity. This does not inform us how complex factors interact and coexist.

A means to overcome the scientific research - coaching practice gap is to provide a dedicated platform for the integration and synthesis of science and application. This may where S\&C coaches and practitioners can work alongside researchers and academic institutions to help find solutions to common coaching problems. One of the main aims of the IUSCA Journal (IUSCA J) is to attempt to find a solution to this problem, by offering a united space for researchers and S\&C coaches to collaborate free of restrictions. ${ }^{7}$ 

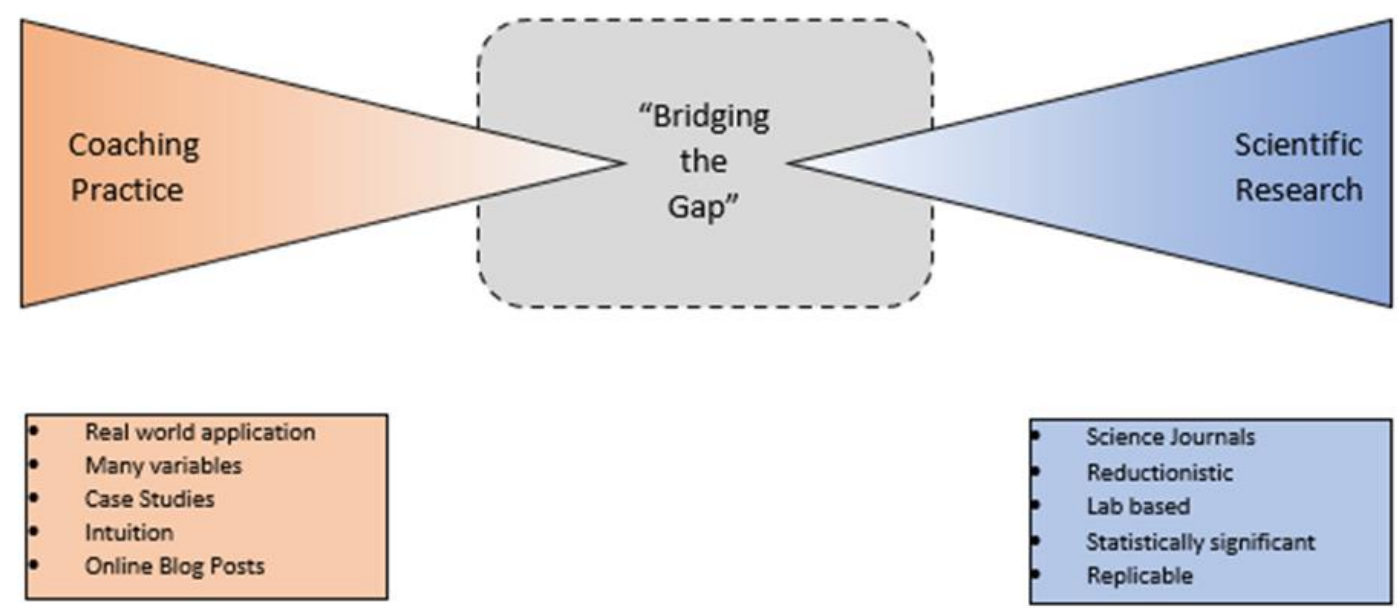

Figure 1. Representation of the areas covered by scientific research and coaching practice, with the "bridging the gap' area in the centre.

As outlined in the IUSCA J editorial, ${ }^{7}$ traditional journal publication can be challenging, with many hurdles that must be overcome, along with significant financial burdens and stylistic restrictions. This may limit publication opportunity for those not associated with a university and many journals conform to a reductionistic focus.

The IUSCA Journal offers a 100\% free publishing route, for any member of the S\&C community. From coaches and practitioners, to lecturers and researchers, students to interns, is afforded the opportunity to submit, review, publish and read IUSCA J articles for free. This is purely driven in an attempt to improve collaboration and stimulate innovation within the S\&C industry. We look forward to the readership joining us to be a part of an open-science movement dedicated to the future of $S \& C$.

\section{References}

1. Lyle J. The transferability of sport coaching research: A critical commentary. Quest. 2018; 70(4): 419-437.

2. Wilson Jr. EB. An Introduction to Scientific Research. New York, NY: Dover Publications Inc.; 1990.

3. Cassidy TG, Jones RL, Potrac P. Understanding sports coaching: The social, cultural and pedagogical foundations of coaching practice. New York, NY: Routledge; 2004.

4. Sanctuary C, Meir R, Sadler I. The seven step approach to the application of sports science in English professional rugby league: Practical considerations in strength and conditioning. International Journal of Sports Science and Coaching. 2012; 7(1): 33-46.

5. Newmark T. Cases in visualization for improved athletic performance. Psychiatric Annals. 2012; 42(10): 385-387.

6. Baker D. A series of studies on the training of high-intensity muscle power in rugby league football players. Journal of Strength and Conditioning Research. 2001; 15(2): 198-209. 11710405

7. Bird SP. Welcome to the International Universities Strength and Conditioning Association Journal: Publishing research with a view to the future. International Universities Strength and Conditioning Association Journal. 2020; 1: 1-2. 